\title{
Levels, trends and determinants of fecundability in Bangladesh: A comparative study using Bangladesh health and demographic survey (BDHS) data
}

\author{
Farhana Hoque $^{1^{*}}$, M. Sekander Hayat Khan ${ }^{1}$, Aminul Haque ${ }^{2,3}$ \\ ${ }^{1}$ Institute of Statistical Research and Training, University of Dhaka, Dhaka, Bangladesh; \\ *Corresponding Author: fhoque@isrt.ac.bd \\ ${ }^{2}$ Institute of Public Health, Heidelberg University, Heidelberg, Germany \\ ${ }^{3}$ Department of Population Sciences, University of Dhaka, Dhaka, Bangladesh
}

Received 4 March 2012; revised 16 April 2012; accepted 8 May 2012

\begin{abstract}
The concept of fecundability derives its importance for the study of human fertility from the fact that it is one of the principal determinants of fertility and is a major standard by which the impact of fertility regulation can be assessed; very few attempts have been made in Bangladesh for estimating fecundability. This study attempts to evaluate the levels, patterns, and trends of fecundability and identify the factors affecting fecundability in Bangladesh based on national surveys of Bangladesh Demographic and Health Survey (BDHS) 2007-1994. Total 9703 ever married women are included in the bivariate and multivariate analyses which reveal that age at first birth, age at marriage and marital duration play an important role in influencing marriage to first birth interval positively and thus fecundability negatively. Although fecundability in Bangladesh showed an increasing trend, but it is very low compared to developed and developing countries.
\end{abstract}

Keywords: Bangladesh; Fecundability; Marriage to First Birth Interval; Fertility and Logistic Regression

\section{INTRODUCTION}

The concept of fecundability - the monthly probability of conception in women-is one of the principle determinants of fertility and one of the most important parameters for studying fertility patterns in different societies. Fecundability affects fertility through its relationship with the average time required for a birth to occur,

*Declaration of Conflicting Interests: The author(s) declared no potential conflicts of interests with respect to the authorship and/or publication of this article. and can also be thought of as the transition probability for the passage from the susceptible state to pregnancy [1]. Marriage to first birth interval and fecundability are two important and interrelated fertility parameters. In homogeneous population marriage to first birth interval is equal to the reciprocal of its fecundability [2].

A woman may take several months to conceive after entering the susceptible period. She may enter the susceptible period by marriage or after resumption of menses after a birth while living with her partner. The time a woman takes to conceive from the time of marriage is called marriage to first birth interval, which is also called waiting time to conception. The women who are more fecund conceive more quickly than those who are less fecund. Fecundability is inversely related to the marriage to first birth interval; the higher the fecundability, the shorter the marriage to first birth interval, and vice versa. In fact, it can be shown that there is an exact inverse relationship between the marriage to first birth interval (W) and fecundability (f) $[(\mathrm{W}=\mathrm{I} / \mathrm{f})]$ in a homogeneous population of women [2-4]. However, in reality, fecundability is not the same for all women because they have different frequencies of intercourse and different biological characteristics. In such a heterogeneous population the average marriage to first birth interval is longer than that in homogeneous case, as with heterogeneity women with the highest fecundability conceive quicker, leaving slower conceivers with decreasing levels of fecundability in successive months [5].

Many attempts have been made to estimate fecundability since Gini [6] first defined fecundability. After introducing the concept of fecundability, Gini proposed an estimate from data on the first live births based on certain assumptions. Henry [7] used this estimate of fecundability to make inferences about the presence of fetal loss. Many authors have studied $[7,8]$ the biases in the estimates of Gini. In 1975 Bongaarts [9] derived a 
new method of estimating the mean and variance of fecundability from the distribution of intervals from marriage to first birth assuming a model for the distribution of intervals from marriage to first birth. Goldman et al. [10] determined the feasibility of estimating fecundability from survey data, giving the limited information on contraception use available from many surveys and the data quality problems associated with reported dates of marriage and dates of birth. In the process, they explored several different procedures for estimation and examined variations in estimates of fecundability by country, time period and women's age.

In practice, fecundability is measured in women who are ovulating regularly, that is, pregnant, sterile or postpartum, anovulatory women are excluded. The term natural fecundability is used non-contraception populations; "total (or physiological)" fecundability considers all conceptions regardless of outcome, including nonimplanted fertilized ova and conceptions aborted spontaneously before the end of the cycle $[9,11]$, while "recognizable" fecundability relates to conceptions recognizable at the end of the conception cycle by the non occurrence of menstruation [9], and "effective" fecundability includes only pregnancies ending in live births [12]. In this study, the term "fecundability" mainly refers to effective fecundability.

Although the theoretical importance of fecundability is beyond question, there are several difficulties in estimating it from direct observation. Fecundability is frequently estimated [2,3,5,13-15] from the distribution of marriage to first birth interval. However, observation on birth intervals is typically censored at higher values, introducing systemic bias into the estimates [16]. In a recent study Goldman and her colleagues [10] examined marriage to first birth interval using World Fertility Survey data from a number of countries and observed that in addition to several methodological problems there were other sources of bias.

Other techniques for estimating fecundability involve: 1) calculations based on coital frequency and the viability of the ovum and sperm $[17,18] ; 2$ ) observations on proportion of women conceiving during a one-month period of exposure to the risk of conception [8,19-22]; and 3) models fitted to the distribution of birth intervals or parities attained within a certain period of time by a group of women [23-25].

In a recent study Islam and Yadava [26] examined fecundability by the model fitting technique to data on the distribution of the number of births to women with a fixed marital duration and studied its levels and trends in Bangladesh. Due to the complex nature of its measurement, as fecundability is not directly observable event, very few attempts have been made in Bangladesh for estimating fecundability. In this analysis, differentials and levels and trends of fecundability of Bangladeshi women have been discussed. Also determinants of fecundability are estimated using Cox's logistic regression model. Patterns of marriage to first birth interval are also examined and fecundability estimated using life table techniques.

\section{METHODS}

The study uses data from the 2007 Bangladesh Demographic and Health Survey [27] (2007 BDHS), which was conducted during February 25 to March 23, 2007 as part of the global Demographic and Health Survey (DHS) under the authority of the National Institute for Population Research and Training of the Ministry of Health and Family Welfare with the financial support of the US Agency for International Development. The BDHS 2007 collected relevant information by randomly selecting and interviewing a sample of 10,996 ever married women age 10 - 49 using two-stage cluster sampling method. In this Study, the women who did not use contraceptive before their first birth are considered for the direct approach of estimation of fecundability. Women who did not conceive within 10 years/120 months of their marriage are excluded assuming that, they are sterile or subfecund. However, this method of estimation of marriage to first birth interval and thus fecundability suffers from selection bias- as it considers only those women who are non-users of contraceptives. To overcome this difficulty life table methodology was applied to estimate the median interval from marriage to first birth. Life table technique considers both users and non-users of contraceptives and thus gives relatively unbiased estimates. This relevant information is available for 1576 ever married women for direct approach and 9703 ever married women for life table approach.

For estimating level, trend and determinants of fecundability in Bangladesh, univariate, bivariate, logistic regression methods and life table approach were used. For trend analysis, in addition to 2007 BDHS data, BDHS data of 1993-1994, 1996-1997, 1999-2000, 2004 [28-31] and Bangladesh Fertility Survey (BFS) data [32, 33] were also used.

Initially, univariate analysis was performed to examine the levels and trend of fecundability. Then bivariate analyses were performed to examine association between socio-economical characteristics and fecundability and discussed fertility-inhibiting effects of the proximate determinants of fecundability. Analyses were performed separately for urban and rural classification.

Logistic regression method was also performed to identify significant determinants of fecundability in Bangladesh. Logistic regression is used to model the relationship between a binary response variable and one 
or more predictor variables, which may be either discrete or continuous. The dependent variable in logistic regression is usually dichotomous, that is, the dependent variable can take the value 1 with a probability of success $\theta$, or the value 0 with probability of failure $1-\theta$. The relationship between the predictor and response variables is not a linear function in logistic regression, Here logit transformation of $\theta$ is given by :

$$
\theta=\frac{e^{\left(\propto+\beta_{1} X_{1}+\beta_{2} X_{2}+\cdots+\beta_{i} X_{i}\right)}}{1+e^{\left(\propto+\beta_{1} X_{1}+\beta_{2} X_{2}+\cdots+\beta_{i} X_{i}\right)}}
$$

where, $\alpha=$ the constant of the equation and $\beta=$ the coefficient of the predictor variables.

An alternative form of the logistic regression equation is:

$$
\begin{aligned}
Y & =\operatorname{Logit}[\theta(X)]=\log \left[\frac{\theta(X)}{1-\theta(X)}\right] \\
& =\alpha+\beta_{1} X_{1}+\beta_{2} X_{2}+\cdots+\beta_{i} X_{i}
\end{aligned}
$$

where, $Y$ is the dependent variable assigning 1 if respondent's marriage to first birth interval is greater than a particular value (cut off point) and 0 if less than or equal to that value. In this analysis, median interval from marriage to first birth which is 22 months in this case was taken as the cutoff point.

\section{RESULTS}

Levels and trend of fecundability by age at first birth, age at first marriage, duration of marriage, type of place of residence, administrative region, education of respondent and husband from BDHS 1993-1994 to BDHS 2007 (Table 1) shown that the fecundability is highest among women whose age at first birth was less than 14 years and lowest among those who have their first birth after reaching 20 years or more. The value of fecundability increases with increase of age at first birth. This comparison does not show any significant change in fecundability from 2004 to 2007, but considerable change is noticed between 1993-1994 and 2004. A slight increasing trend in fecundability is notice from 1996-1997 (Figure 1).

Table 2 gives the fecundability transition by marital duration. Estimates are derived from Bangladesh fertility survey (BFS) data of 1975 and 1989 and Bangladesh demographic and health survey (BDHS) data from 19931994 to 2007.

The overall fecundability in 1975, 1989 and 19931994 were $0.06,0.05$ and 0.033 per month suggesting a declining trend in fecundability in Bangladesh over time. This decline may be mainly due to the increased use of contraceptives. But from 1996-1997 a slightly increasing trend can be noticed in the fecundability. Although there was a small declining change in fecundability among

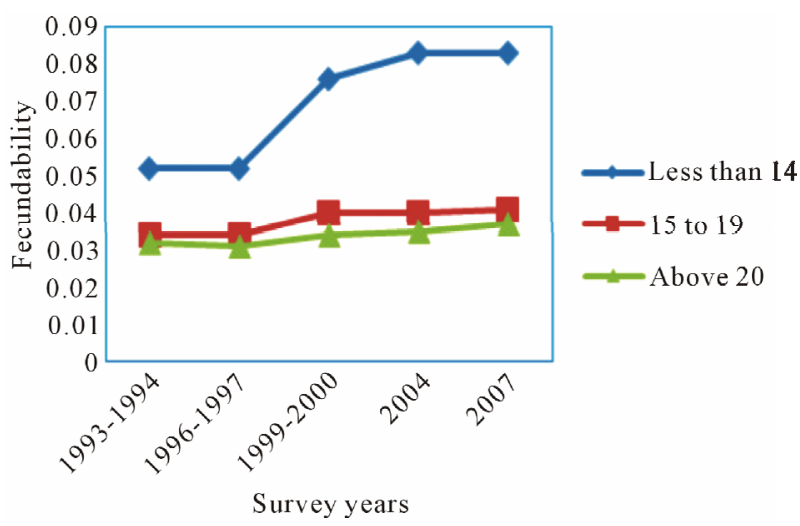

(a)

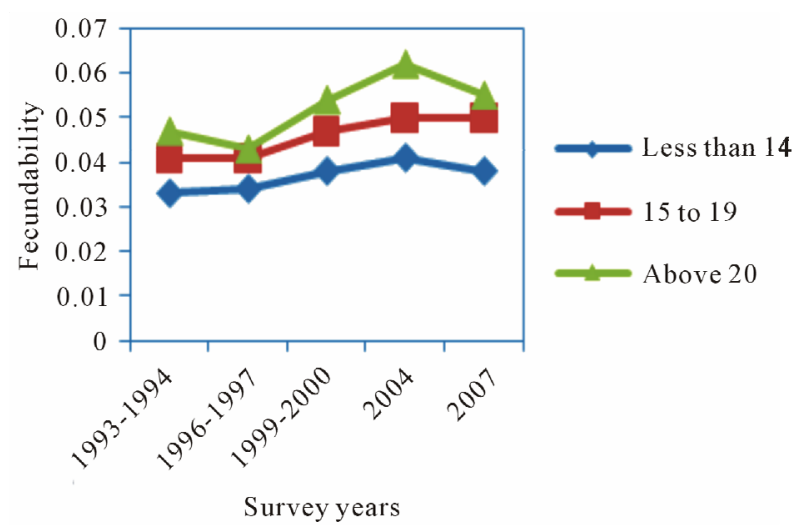

(b)

Figure 1. (a) Fecundabiility by years preceding the survey for different age at $1^{\text {st }}$ birth; (b) Fecundability by years preceding the survey for different age at marriage.

women married for 5 - 9 years, 10 - 14 years and 15 - 19 years in 1989, a somewhat different trend was noticed in 1975 in the fecundability which peaked at $10-14$ years of marital duration and then declined thereafter. It is evident that the average fecundability for different marital periods in 1989 is consistently lower than that in 1975. The fecundability was observed to decline with an increase in marital duration in each year. However, the value of fecundability is higher for $0-4$ year marital duration group in 2007 as compared to 1993-2004 and decline thereafter. The average value of fecundability was observed to increase from 0.033 per month in 19931994 to 0.041 per month in 2007 (Figure 2).

Considering direct approach of estimation, the median interval from marriage to first birth was found to be 22.0 months, which provides an estimate of the fecundability at 0.045 per month (Table 3 ). The median interval from marriage to first birth provided by life table approach was found to be 21.0 months which was slightly lower comparative to the median interval marriage to first birth interval obtained by direct estimation method. The corresponding estimate of fecundability was 0.047 which is higher than the direct estimate $(0.045)$. 
Table 1. Fecundability trends of Bangladesh from 1993-2007 by selected fecundability differentials.

\begin{tabular}{|c|c|c|c|c|c|}
\hline $\begin{array}{l}\text { Background } \\
\text { characteristics }\end{array}$ & $\begin{array}{l}\text { 1993-1994 } \\
\text { BDHS }\end{array}$ & $\begin{array}{l}\text { 1996-1997 } \\
\text { BDHS }\end{array}$ & $\begin{array}{l}\text { 1999-2000 } \\
\text { BDHS }\end{array}$ & $\begin{array}{c}2004 \\
\text { BDHS }\end{array}$ & $\begin{array}{c}2007 \\
\text { BDHS }\end{array}$ \\
\hline \multicolumn{6}{|l|}{ Age at first birth } \\
\hline$\leq 14$ & 0.052 & 0.052 & 0.076 & 0.083 & 0.083 \\
\hline $15-19$ & 0.034 & 0.034 & 0.040 & 0.040 & 0.041 \\
\hline $20+$ & 0.032 & 0.031 & 0.034 & 0.035 & 0.037 \\
\hline \multicolumn{6}{|l|}{ Age at first marriage } \\
\hline$\leq 14$ & 0.033 & 0.034 & 0.038 & 0.041 & 0.038 \\
\hline $15-19$ & 0.041 & 0.041 & 0.047 & 0.050 & 0.050 \\
\hline $20+$ & 0.047 & 0.043 & 0.054 & 0.062 & 0.055 \\
\hline \multicolumn{6}{|l|}{ Marital duration } \\
\hline $0-9 \mathrm{yr}$ & 0.041 & 0.041 & 0.047 & 0.050 & 0.058 \\
\hline $10-24 \mathrm{yr}$ & 0.034 & 0.035 & 0.038 & 0.040 & 0.042 \\
\hline $25+\mathrm{yr}$ & 0.030 & 0.033 & 0.038 & 0.043 & 0.037 \\
\hline \multicolumn{6}{|c|}{ Type of place of residence } \\
\hline Urban & 0.040 & 0.041 & 0.041 & 0.045 & 0.043 \\
\hline Rural & 0.035 & 0.037 & 0.041 & 0.044 & 0.041 \\
\hline \multicolumn{6}{|l|}{ Administrative region } \\
\hline Barishal & 0.033 & 0.040 & 0.038 & 0.041 & 0.041 \\
\hline Chittagong & 0.038 & 0.041 & 0.047 & 0.047 & 0.047 \\
\hline Dhaka & 0.037 & 0.034 & 0.038 & 0.047 & 0.041 \\
\hline Rajshahi & 0.034 & 0.035 & 0.041 & 0.041 & 0.040 \\
\hline Khulna & 0.033 & 0.035 & 0.037 & 0.040 & 0.041 \\
\hline Sylhet & - & 0.038 & 0.045 & 0.047 & 0.047 \\
\hline \multicolumn{6}{|c|}{ Respondent currently working } \\
\hline No & 0.037 & 0.037 & 0.043 & 0.045 & 0.047 \\
\hline Yes & 0.035 & 0.037 & 0.039 & 0.045 & 0.040 \\
\hline \multicolumn{6}{|l|}{ Education of respondent } \\
\hline No education & 0.035 & 0.037 & 0.041 & 0.041 & 00.041 \\
\hline Primary education & 0.037 & 0.038 & 0.041 & 0.045 & 00.043 \\
\hline Secondary or higher & 0.045 & 0.040 & 0.050 & 0.052 & 00.052 \\
\hline \multicolumn{6}{|l|}{ Education of husband } \\
\hline No education & 0.037 & 0.035 & 0.041 & 0.043 & 00.041 \\
\hline Primary education & 0.034 & 0.038 & 0.041 & 0.041 & 00.041 \\
\hline Secondary higher & 0.040 & 0.038 & 0.041 & 0.050 & 00.050 \\
\hline All & 0.037 & 0.037 & 0.041 & 0.045 & 0.045 \\
\hline
\end{tabular}

Abbreviations: BDHS, Bangladesh Demographic and Health Survey. 
Table 2. Estimated average fecundability by marital duration.

\begin{tabular}{cccccccc}
\hline Marital duration & $\mathbf{1 9 7 5}$ BFS & 1989 BFS & \multicolumn{1}{c}{ 1993-1994 BDHS 1996-1997 BDHS 1999-2000 BDHS } & 2004 BDHS & 2007 BDHS \\
\hline $\mathbf{0}-\mathbf{4}$ & & & 0.050 & 0.055 & 0.058 & 0.055 & 0.067 \\
$\mathbf{5}-\mathbf{9}$ & 0.061 & 0.053 & 0.037 & 0.038 & 0.043 & 0.047 & 0.050 \\
$\mathbf{1 0}-\mathbf{1 4}$ & 0.067 & 0.051 & 0.033 & 0.035 & 0.040 & 0.041 & 0.043 \\
$\mathbf{1 5}-\mathbf{1 9}$ & 0.058 & 0.049 & 0.030 & 0.032 & 0.034 & 0.037 & 0.038 \\
$\mathbf{2 0}-\mathbf{2 4}$ & 0.047 & 0.043 & 0.027 & 0.027 & 0.031 & 0.035 & 0.037 \\
All & 0.062 & 0.051 & 0.033 & 0.034 & 0.038 & 0.041 & 0.041 \\
\hline
\end{tabular}

Abbreviations: BFS, Bangladesh Fertility Survey. Source ${ }^{12}$ : BFS 1975, BFS 1989.

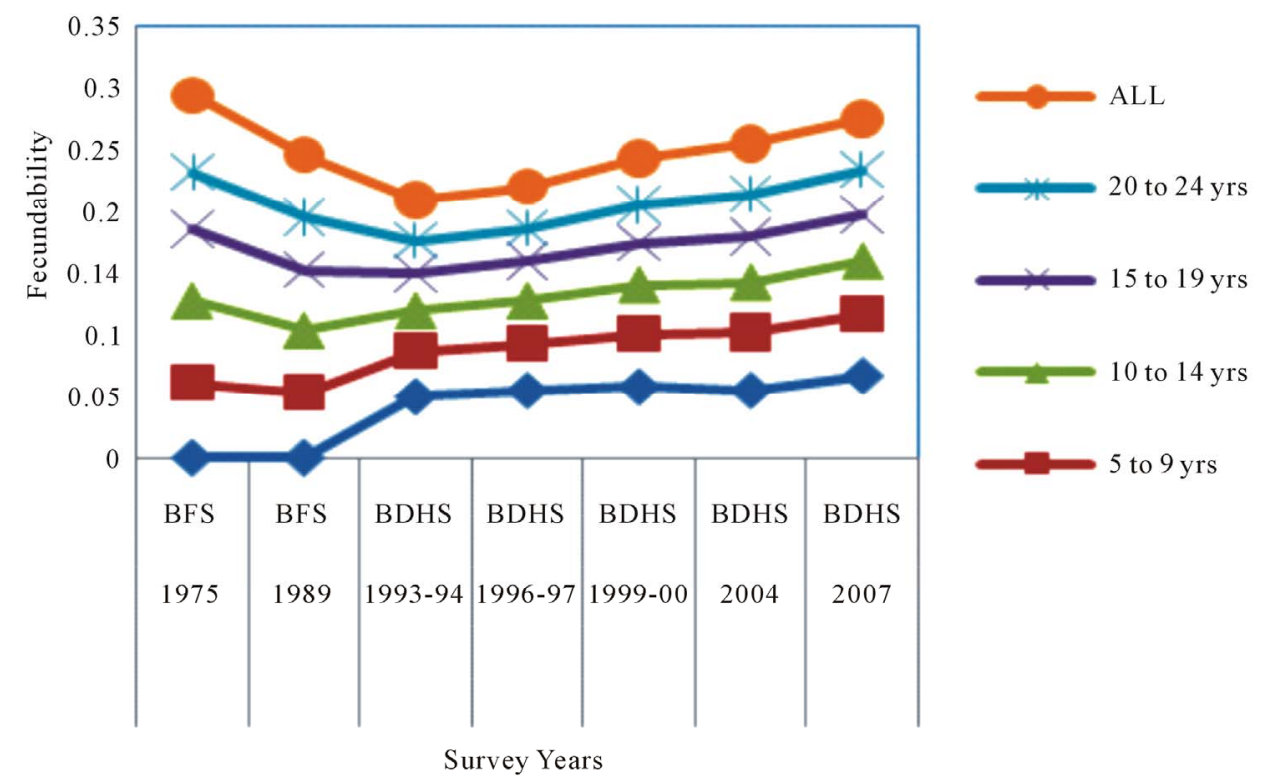

Figure 2. Fecundability from 1993 to 2007 by marital duration.

The Cox's logistic regression analysis shown that age at marriage was an important significant factor which influenced marriage to first birth interval positively and thus fecundability negatively. The implication of the odds ratio is that women who married at ages between 15 to 19 are 12.574 times likely to have a first birth compared to those who married at age less than 14. Again for women who married at ages 20 and above the odds ratio is 78.815 which indicate that this group of women were 78.815 times likely to conceive compared to the women whose age at marriage is below 14. Age at first birth is also appeared to be another important significant predictor of marriage to first birth interval. The women who conceive at lower ages were likely to have a shorter marriage to birth interval than the women who conceive at higher ages. The odds ratio for women who conceive between ages 15 to 19 , and 20 and above are 0.253 and 0.060 respectively which indicate that women who conceive at higher ages were likely to take longer birth interval compared to those who conceive at lower ages.
Duration of marriage continues to have very strong and positive independent effect on the first birth interval with the likelihood of birth spacing increasing significantly as the marital duration increases. Further, the odds ratio shown that women with marital duration greater than 25 years were almost 2.887 times as likely as the women whose marital duration were less than 9 years to have a first birth interval (Table 4).

\section{DISCUSSION}

Bangladesh Demographic and Health Survey used a nationally representative sample for estimating demographic and health related scenario of the country. In Western countries [34] such as Denmark (Copenhagen), France (Paris), Scotland (Edinburgh) and Finland (Turku) measured fecundability in order to make a comparison of marriage to first birth interval among couples from these countries. Although fecundability is an important fertility parameter to make idea about any country's fertility 
Table 3. The direct and life table approach for estimating fecundability (per month) by different fecundability differentials.

\begin{tabular}{|c|c|c|c|c|}
\hline \multirow{2}{*}{ Background characteristics } & \multicolumn{2}{|c|}{ Direct approach of estimation } & \multicolumn{2}{|c|}{ Life table approach of estimation } \\
\hline & $\begin{array}{l}\text { Marriage to first birth } \\
\text { (months) }\end{array}$ & $\begin{array}{l}\text { Fecundability } \\
\text { (per month) }\end{array}$ & $\begin{array}{l}\text { Marriage to first birth } \\
\text { (months) }\end{array}$ & $\begin{array}{c}\text { Fecundability } \\
\text { (per month) }\end{array}$ \\
\hline \multicolumn{5}{|l|}{ Place of residence } \\
\hline Rural & 22 & 0.045 & 22 & 0.045 \\
\hline Urban & 22 & 0.045 & 21 & 0.047 \\
\hline \multicolumn{5}{|l|}{ Administrative region } \\
\hline Barishal & 24 & 0.041 & 23 & 0.043 \\
\hline Chittagong & 21 & 0.047 & 20 & 0.050 \\
\hline Dhaka & 24 & 0.041 & 22 & 0.045 \\
\hline Khulna & 25 & 0.040 & 23 & 0.043 \\
\hline Rajshahi & 24 & 0.041 & 21 & 0.047 \\
\hline Sylhet & 21 & 0.047 & 19 & 0.052 \\
\hline \multicolumn{5}{|l|}{ Marital duration } \\
\hline $0-9 \mathrm{yr}$ & 17 & 0.058 & 17 & 0.058 \\
\hline $10-24 \mathrm{yr}$ & 23.5 & 0.042 & 23 & 0.043 \\
\hline $25+\mathrm{yr}$ & 27 & 0.037 & 27 & 0.037 \\
\hline \multicolumn{5}{|l|}{ Age of respondent at first birth } \\
\hline$\leq 14$ & 12 & 0.083 & 12 & 0.083 \\
\hline $15-19$ & 24 & 0.041 & 23 & 0.043 \\
\hline $20+$ & 27 & 0.037 & 26.5 & 0.037 \\
\hline \multicolumn{5}{|l|}{ Age at first marriage } \\
\hline$\leq 14$ & 26 & 0.038 & 24 & 0.041 \\
\hline $15-19$ & 20 & 0.050 & 20 & 0.050 \\
\hline $20+$ & 18 & 0.055 & 18 & 0.055 \\
\hline \multicolumn{5}{|l|}{ Occupation of the husband } \\
\hline Professionals & 20 & 0.050 & 23 & 0.043 \\
\hline Business & 22 & 0.045 & 21 & 0.047 \\
\hline Non agricultural work & 23 & 0.043 & 21 & 0.047 \\
\hline Agricultural work & 22 & 0.045 & 22 & 0.045 \\
\hline Others & 20.5 & 0.048 & 21 & 0.047 \\
\hline \multicolumn{5}{|l|}{ Sex of household head } \\
\hline Male & 22 & 0.045 & 21 & 0.047 \\
\hline Female & 24 & 0.041 & 22 & 0.045 \\
\hline \multicolumn{5}{|l|}{ Husband lives in a house } \\
\hline Yes & 22 & 0.045 & 21 & 0.047 \\
\hline No & 23 & 0.043 & 22 & 0.045 \\
\hline
\end{tabular}


Continued

Number of living children

$\begin{array}{ccccc}0-5 & 22 & 0.045 & 21 & 0.047 \\ 6-10 & 22.5 & 0.044 & 23 & 0.043 \\ 11+ & 10 & 0.100 & 21 & 0.047\end{array}$

\section{Religion}

Muslim

Non-muslim

0.045

0.040

21

0.047

0.045

Education of respondent

No education
Primary education
Secondary or higher

Education of husband

No education
Primary education
Secondary or higher

\section{Watch television}

$\begin{array}{ll}\text { No } & 24 \\ \text { Yes } & 21\end{array}$

\section{Listen radio}

$$
\text { No }
$$$$
\text { Yes }
$$

Socio economic status

$\begin{array}{ll}\text { Poorest } & 25 \\ \text { Poorer } & 22 \\ \text { Middle } & 22 \\ \text { Richer } & 21 \\ \text { Richest } & 21\end{array}$

0.041

0.047

0.043

0.047

0.040

0.045

0.045

0.047

0.047
0.043

0.047

0.050

0.045

0.047

0.047

0.045

0.045

0.047

0.047

0.045

$22 \quad 0.045$

0.045

0.045

0.047

0.047

0.047

Ever use of any method

$\begin{array}{ll}\text { Yes } & --- \\ \text { No } & 22 \\ \text { All } & \mathbf{2 2}\end{array}$

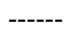

0.045

0.045
0.047

0.045

0.047 
Table 4. Logistic regression analysis for estimating fecundability differentials.

\begin{tabular}{|c|c|c|c|c|}
\hline Variables & Beta Coefficient B & S.E (B) & Significance & Odds ratio \\
\hline \multicolumn{5}{|l|}{ Age at first marriage } \\
\hline$\leq 14(\mathrm{r})$ & ----- & ----- & 0.000 & 1.000 \\
\hline $15-19$ & 2.532 & 0.229 & 0.000 & 12.574 \\
\hline $20+$ & 4.637 & 0.315 & 0.000 & 78.815 \\
\hline \multicolumn{5}{|l|}{ Age at 1st birth } \\
\hline$\leq 14(\mathrm{r})$ & ------- & ------ & 0.000 & 1.000 \\
\hline $15-19$ & -1.373 & 0.155 & 0.000 & 0.253 \\
\hline $20+$ & -2.811 & 0.336 & 0.000 & 0.060 \\
\hline \multicolumn{5}{|l|}{ Marital Duration } \\
\hline $0-9$ yr (r) & ----- & ------- & 0.000 & 1.000 \\
\hline $10-24 \mathrm{yr}$ & 0.480 & 0.154 & 0.002 & 1.616 \\
\hline $25+\mathrm{yr}$ & 1.060 & 0.179 & 0.000 & 2.887 \\
\hline \multicolumn{5}{|l|}{ Division } \\
\hline Sylhet (r) & ----- & ------- & 0.131 & 1.000 \\
\hline Barishal & 0.205 & 0.247 & 0.407 & 1.228 \\
\hline Chittagong & -0.185 & 0.166 & 0.266 & 0.831 \\
\hline Dhaka & 0.146 & 0.197 & 0.459 & 1.157 \\
\hline Khulna & 0.530 & 0.267 & 0.048 & 1.699 \\
\hline Rajshahi & 0.177 & 0.234 & 0.450 & 1.194 \\
\hline \multicolumn{5}{|l|}{ Place of residence } \\
\hline Urban (r) & ------ & ----- & ------- & 1.000 \\
\hline Rural & -0.021 & 0.151 & 0.891 & 0.980 \\
\hline \multicolumn{5}{|c|}{ Respondent currently working } \\
\hline No (r) & ------- & ------- & ------ & 1.000 \\
\hline yes & -0.110 & 0.153 & 0.471 & 0.896 \\
\hline \multicolumn{5}{|l|}{ Education of respondent } \\
\hline No education (r) & ----- & ------ & 0.765 & 1.000 \\
\hline Primary education & 0.069 & 0.156 & 0.659 & 1.071 \\
\hline Secondary or higher & -0.066 & 0.202 & 0.743 & 0.936 \\
\hline
\end{tabular}

Abbreviations: r, reference category, S.E (B), standard error, $\mathrm{p}<0.000$; indicates standardized parameter estimates; Source ${ }^{23}$ : Bangladesh Demographic and Health Survey, 2007.

situation; the BDHS did not use and estimate this parameter in their report. This study found that life table approach for estimating fecundability gives more precise estimate than direct approach of estimation. Very few attempts have been taken to measured fecundability in Bangladesh using life table approach. The estimate of fecundability in Bangladesh is very close to the estimates of fecundability in the neighboring country of India. Compared to other developed and developing countries, the fecundability in Bangladesh is very low [26]. The fecundability during the first few years of marriage could be lower due to adolescent sterility. This is also reflected in our trend analysis which showed that from 1993 to 2007 , the average fecundability during the first years of 
marriage (less than 14 years) was lower than that between 15 - 19 years of marriage. As compared to western countries where fecundability levels have been reported $[9,14,35,36]$ to range from 0.15 to 0.31 , our estimates are much lower. Bongaarts [4] obtained the average fecundability of 0.37 for five historical populations (Crulai, Tourouvre and Perche, Geneva, Tunis, Canada). Several studies have indicated that there is a positive relationship between fecundability and nutrition level [37,38]. It implies that women of developed countries enjoy different socio-economic, demographic, nutritional and medical factors which increased their probability to be pregnant in a single menstruation. On the other hand lower fecundability of the women indicates that above factors are not in a favorable condition for the Bangladeshi women. We need to pay attention to improve these factors in our country.

The higher fecundability for recent years indicates that fecundability level is increasing in Bangladesh. It may happen due to social and behavioral factors like low number of child death during pregnancy period, nutritional status improvement, low contraceptive use rate/or lack off effective use of contraception. It may occur due to the continuous implementation of recent different health sector programs by government and development partners and NGOs. Women with infecundity is badly mistreated by their family as well as by the society in Bangladesh. These women are physically and mentally abused for their inefficiency to be mother. So rising fecundability indicates that number of infecundity caused by socio-economic, nutritional or medical factors are going to reduce. Women with early age at marriage were usually experienced a longer first birth interval than their counterparts with higher age at marriage. This analysis implies that late marrying women are attempting to catch up for the years lost in the single state and hence having shorter birth interval.

From life table estimate the median marriage to first birth interval for rural population is found 22.0 months while this value is little shorter (21.0 months) for urban population. This result provides a higher fecundability (0.047) for urban area comparative to rural area (0.045). An interesting thing is notable that though in rural areas fecundability is low but total fertility rate is high in rural area (2.8) comparative to urban area (2.4). The BDHS report explained that this is happened because contraceptive practice in urban area is high; 62 percent of women in urban area use contraceptive while this value is 54 percent for rural area [27]. The low fecundability in rural area is attributed to the low nutritional status, low average age at marriage and low socio-economic condition comparative to urban areas. We need to explore more why and what are the different socio, economical, behavioral factors are associated behind the differences in fecundability among rural and urban areas to make effective implementation of any health population sector program. Future demographers, population experts and BDHS research committee will importantly explore the answer of the questions arise in regards to the lower level of fecundability of the Bangladesh women and will incorporate fecundability in BDHS analysis.

\section{CONCLUSION}

A slightly increasing trend in fecundability was noticed in recent years in Bangladesh. But compared to other developed and developing countries, the fecundability in Bangladesh is very low. Age at marriage was the most important factor explaining fecundability for every sub-group of the study population. Women marrying at higher age have tendency to conceive quickly than those who marry at a lower age. The direct and life table approach of estimation procedure give closer estimate of fecundability. Logistic regression analysis identified age at marriage, age at first birth and marital duration were important significant factors which influence marriage to first birth interval positively and thus fecundability negatively. This complex issue needs to be addressed by the researchers, policy makers and demographers to map out the fertility level of Bangladesh. As a highly populated country, with huge number of women in reproductive age, any future population sector program, population projection or policies might be ineffective and population problem can be compound, without very microscopic attention to the complex issue.

\section{VALIDITY AND LIMITATIONS OF DATA}

Bangladesh Demographic and Health Survey (BDHS) is the nationally representative household survey of Bangladesh. However, this paper presented the findings based on the analysis of secondary data. Due to financial and time constrain, the paper could not add primary data in supporting the BDHS data.

\section{ACKNOWLEDGEMENTS}

The authors acknowledge the cooperation of the Institute of Statistical Research and Training, University of Dhaka, Bangladesh and NIPORT for completing the research. The author(s) received no financial support for the research and/or authorship of this article.

\section{REFERENCES}

[1] Perrin, E.B. and Sheps, M.C. (1964) Human reproduction: A stochastic process. Biometrics, 20, 28-45.

[2] Sheps, M.C. and Menken, J.A. (1973) Mathematical models of conception and birth. University of Chicago Press, Chicago. 
[3] Henry, L. (1953) Fecundabilite des Mariages in. Presses Universitaires de France, Paris.

[4] Bongaarts, J. and Potter, R.J. (1983) Fertility biology and behavior: An analysis of the proximate determinants of fertility. Academic Press, New York.

[5] Potter, R.G. and Parker, M.P. (1964) Predicting the time required to conceive. Population Studies, 18, 99-116.

[6] Gini, C. (1924) Premieres Recherches sur la fecundabilite de fa Femme. Proceedings of International Mathematical Congress, Toronto, 11-16 August 1924, 889-892.

[7] Henry, L. (1964) Mortalite intra-uterine et fecundabilite. Population, 19, 899-940. doi:10.2307/1525891

[8] Sheps, M.C. (1965) An analysis of reproductive patterns in an American isolate. Population Studies, 19, 65-80.

[9] Bongaarts, J. (1975) A method for the estimation of fecundability. Demography, 12, 645-660. doi: $10.2307 / 2060719$

[10] Goldman, N., Westoff, C.F. and Paul, L.E. (1985) Estimation of fecundability from survey data. Studies in Family Planning, 16, 232-259. doi:10.2307/1966998

[11] Leridon, H. (1977) Human fertility: The basic components. University of Chicago Press, London.

[12] Henry, L. (1957) Fecondite it famille: Models mathematiques. Population, 12, 413-444. doi:10.2307/1524504

[13] Sheps, M.C. (1964) On the time required from for conception. Population Studies, 18, 85-97. doi:10.2307/2172633

[14] Jain, A.K. (1969) Fecundability and its relation to age in a sample of Taiwanese women. Population Studies, 23, 69-85.

[15] Majumdar, H. and Sheps, M.C. (1970) Estimators of a type 1 geometric distribution from observation on conception times. Demography, 7, 349-360. doi: $10.2307 / 2060154$

[16] Cox, D.R. and Oakes D. (1984) Analysis of survival data. Chapman and Hall, London.

[17] Class, D.U. and Grebenik, E. (1954) The trend and pattern of fertility in great britain: A report on the family census of 1946. H M Stationary Office, London.

[18] Lachenbruch, P.A. (1967) Frequency and timing of intercourse: Its relation to the probability of conception. Population Studies, 21, 23-31.

[19] Henry, L. (1980) Fertility of marriages: A new method of measurement, population studies transition. United Nations, New York.

[20] Tietze, C., Guttmacher, A.F. and Rubin, S. (1950) Time required for conception in 1727 planned pregnancies. Fertility and Sterility, 1, 338-346.

[21] Potter, R.G., Jr. (1961) Length of the fertile period. The Milbank Memorial Fund Quarterly, 39, 132-162. doi:10.2307/3348639

[22] Barrett, J.C. (1969) A monte carlo simulation of human reproduction. Genus, 25, 1-22.

[23] Brass, W. (1958) The distribution of births in human population. Population Studies, 12, 59-72.

[24] Singh, S.N. (1963) Probability models for the variation in the number of births per couple. Journal of the American Statistical Association, 58, 721-727. doi:10.1080/01621459.1963.10500882

[25] Singh, S.N. (1969) Low estimate of fecundability. International Union for the Scientific Study of Population, London.

[26] Islam M.M. and Yadava R.C. (1997) Estimation of fecundability: Levels and trends in Bangladesh. Journal of Family Welfare, 43, 13-20.

[27] Mitra and Associates, and Macro International Inc. (2009) Bangladesh demographic and health survey 2007. National Institute of Population Research and Training, Dhaka.

[28] Mitra and Associates, and Macro International Inc. (1994) Bangladesh demographic and health survey 1993-94. National Institute of Population Research and Training, Dhaka.

[29] Mitra and Associates, and Macro International Inc. (1997) Bangladesh demographic and health survey 1996-97. National Institute of Population Research and Training, Dhaka.

[30] Mitra and Associates, and Macro International Inc. (2001) Bangladesh demographic and health survey 1999-00. National Institute of Population Research and Training, Dhaka.

[31] Mitra and Associates, and Macro International Inc. (2005) Bangladesh demographic and health survey 2004. National Institute of Population Research and Training, Dhaka.

[32] Haq, N. and Cletand J. (1976) Bangladesh fertility survey 1975. National Institute of Population Research and Training (NIPORT), Dhaka.

[33] Haq, N. and Cletand, J. (1990) Bangladesh fertility survey 1989. National Institute of Population Research and Training (NIPORT), Dhaka.

[34] Jensen, T.K., Slama, R., Ducot, B., et al. (2001) Regional differences in waiting time to pregnancy among fertile couples from four European cities. Human Reproduction, 16, 2697-2704. doi:10.1093/humrep/16.12.2697

[35] Bongaarts, J. (1978) A framework for analyzing the proximate determinants of fertility. Population and Development Review, 4, 105-132. doi:10.2307/1972149

[36] James, W.H. (1973) The fecundity of US women. Population Studies, 27, 493-500.

[37] Chowdhury, A.K.M.A. (1978) Effect of maternal nutrition on fertility in rural Bangladesh. In: Mosely, W.H., Ed., Nutrition and Human Reproduction, Plenum Press, New York, 401-410.

[38] Menken, J.A., Trussel, J. and Watkins, S. (1981) The nutriation fertility link: An evaluation of the evidence. The Journal of Interdisciplinary History, 11, 425-441. doi: $10.2307 / 203626$ 


\section{ABBREVIATIONS}

BDHS: Bangladesh Health and Demographic Survey;

DHS: Health and Demographic Survey;

BFS: Bangladesh Fertility Survey;

NIPORT: National Institute of Population and Research

Training. 